\title{
Between Unwanted and Disowned Child: A Comparative Study of Adoption of Self-Service Systems
}

\author{
Bob Travica \\ University of Manitoba, Winnipeg, Manitoba, Canada \\ btravica@cc.umanitoba.ca
}

\begin{abstract}
This article presents a comparative case study of self-service based enterprise systems in two companies. The study used an information politics (infopolitics) approach in order to investigate issues surrounding adoption of the systems. The main finding is that information-based power in its different modalities, infopolitical agendas, and infopolitical behaviors of fight and flight influenced lower rates of adopting these systems. The study contributes to theorizing on selfservice systems adoption.
\end{abstract}

Keywords: Information system adoption, ERP system, organizational politics, information politics

\section{Introduction}

This article presents a comparative case study of information systems that are based on enterprise resource planning (ERP) software and are designed to be used in a self-service mode: a human resources management system (HRMS) in Utilities Company, and a customer relationship management system (CRMS) in Telco (both names are disguised). ERP software allows for integrating information management across organizational departments in support of cross-functional business processes and creating a holistic picture of an organization. A self-service system requires that end-users use the system directly, with no help from an intermediary. Data entry, querying, and other system tasks are the duty of casual users rather than specially trained power users (clerks or information system professionals). For example, a manager has to use the system for approving the reported work hours, rather than having a secretary perform a part of the process. The application domain of self-service information systems (IS) expands, which underlines the need to advancing research on them.

While the literature on implementation of enterprise resource planning systems (ERP) is not lacking, the self-service variant of these systems is still insufficiently studied (e.g., Lapointe \& Ri-

Material published as part of this publication, either on-line or in print, is copyrighted by the Informing Science Institute. Permission to make digital or paper copy of part or all of these works for personal or classroom use is granted without fee provided that the copies are not made or distributed for profit or commercial advantage AND that copies 1) bear this notice in full and 2) give the full citation on the first page. It is permissible to abstract these works so long as credit is given. To copy in all other cases or to republish or to post on a server or to redistribute to lists requires specific permission and payment of a fee. Contact Publisher@InformingScience.org to request redistribution permission. vard, 2005; Larsen \& Myers, 1999; Stein, Hawking, \& Wyld, 2005; Travica, 2007, 2008). Still, the problem of the key factors playing part in adoption of intra-organizational self-service systems requires more focused research and new insights reaching beyond ERP success factors because these systems increase dramatically the user body, including potentially all organization members. Organizational politics can make an im- 
pact on new work processes since access to data is changed and data flows modified; these changes are likely to impinge on the established distribution of power (Markus, 1983; Zuboff, 1984). Political agendas, thus, are triggered, and political maneuvering is set in motion.

The complexity of the user pool brings to bear a potential of multiple battlegrounds cutting across occupational and departmental boundaries. For instance, managers-users may have different requirements than professionals-users (Travica, 2008). A tension between the centralization and decentralization pulls (Mintzberg, 1979), that is the executive versus departmental management, may be heightened. Executives may gain from centralizing information management, which translates into a loss at the level of department management. Moreover, the IS staff supporting these systems is likely to be exposed to a broader front of system requirements and could find it challenging to balance its response without offending any user group (e.g., fixing a user interface feature that bothers one user group may anger another user group that has become familiar with that feature). It may be nearly impossible to maintain the system via regular updates of software without disrupting operations of some user groups rather than others. On the other hand, many more users than ever before find themselves being dependent on the IT expertise the ERP staff commands. Of course, other than political aspects can be involved in adoption of self-service systems.

The comparative case study presented in this article was guided by the research question:

What are the critical factors for adoption of the self-service systems in the two companies investigated?

The study used the conceptual and analytical framework called Information View of Organization (Travica, 2003, 2004, 2005a, 2005b) that has been useful in shedding the light on these broader organizational aspects involved in system adoption situations (Travica, 2007, 2008).

\section{The Concept of Infopolitics}

This study aimed at understanding political aspects of adoption of self-service systems in two organizations, and particularly those political aspects that have to do with information and IT involved in the systems under study. The concept of infopolitics (short for "information politics") has lent itself as an appropriate theoretical basis for this research problem. This concept comes from the Information View of Organization (IVO) (Travica, 2003, 2004, 2005a, 2005b, 2006), and it refers to that part of organizational politics that revolves around information and IT. Organizational information and IT influence organizational politics and are influenced by it. For example, possession of information and IT can be the source of power. In this scenario, IT and information are the resources that one party controls, while another party depends on it. In other words, IT can be the medium for managing information in order to establish or alter the power relationship.

The concept of infopolitics has support both in the management and IS literature. For example, the well-known concept of expert power (Crozier, 1964) can be understood as a kind of information-related power because knowledge (a particular instance of information in the IVO parlance) is the power basis. Beniger (1986) provided a compelling argument that the potentials and actual uses of communication technology qualify it as a mighty lever of control. Danziger, Dutton, Kling, and Kraemer (1982) and Orlikowski (1992) found independently of each other that the speed, direction, content, and pattern of information flows influence power in organizations. Zuboff (1984) and Danziger and colleagues (1982) found that an existing distribution of power can be strengthened through automation of organization. It has been widely recognized that centralization/decentralization of information and IT can accompany the introduction of new ISs, and that these changes modify power distribution (Hanseth, Ciborra, \& Braa, 2001; Markus, 1983; Orlikowski \& Yates, 1994; Travica, 1999; Zuboff, 1984). Different patterns of codifying and dif- 
fusing information complement different forms of structuring power and organizations, such as bureaucracy and clan (Boisot, 1987, 1998). Moreover, power relationships in the context of the system life cycle have also been studied (Silva \& Backhouse, 2002; Silva \& Hirschheim, 2008). A comprehensive discussion on the study of organizational politics in connection with IS and IT appears in the review by Jasperson and colleagues (2002).

IVO assumes that infopolitics is a distinct part of organizational politics (see Figure 1), which merits separate research. Another assumption is that infopolitics influences system adoption, which is also depicted in Figure 1. (Note that infopolitics is also related to other IS-related issues - IS design/development, IS use, IS management, and IS evaluation; these are not shown in Figure 1 because they are not relevant for this discussion.)

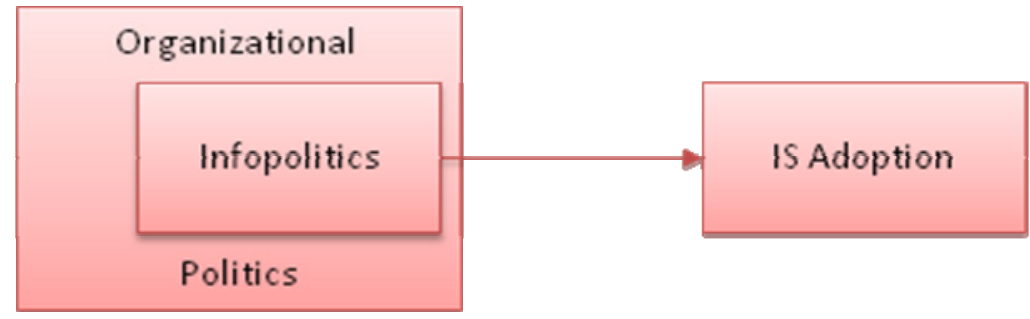

Figure 1. The Relationship between Infopolitics and IS Adoption in IVO

IVO differentiates between three domains of infopolitics: infopower, infoagenda, and infopolitical fight/flight. Infopower refers to the ability of subject A to make subject B do something that B otherwise would not do, based on B's perception that A has certain capabilities related to information and IT. Infopower can come from three sources: control over data/IT, meaning management, and expert power.

Control over data/IT implies A can change B's conduct based on A's control over data or IT. This concept formalizes the popular credo that "information is power." Theoretical foundations can be found in organization theory (e.g., Burns \& Stalker, 1961; Hersey, Blanchard, \& Natemeyer, 1979; Pettigrew, 1972). A typical example of this sort of infopower refers to a manager that has more privileges in accessing business data than the subordinates. The manager transforms the data into meaning and knowledge of the organization and business, and on this basis, the manager makes decisions that affect the subordinates. Controlling allocation of physical IT assets and of access to IS are examples of using IT as the source of infopower.

Meaning management refers to infopower that is based on B's expectation that A can mediate a right understanding of reality. This category of infopower can exist with or without help of IT. Meaning management implies a relationship that is stable in time relative to temporary shifts in opinion caused by communication influence (e.g., persuasion) and is akin to Goffman's (1967) concept of impression management. Bradshaw-Camball \& Murray (1991) described an example of meaning management in the study of a hospital in which administrators systematically dramatized financial data in the process of budget planning. In so doing, they invoked an illusionary definition of reality in the mind of the hospital's board, employees, and the Ministry of Health. Another example is a study of an instant messaging system used in a high-tech company, which was conducted by Quan-Haase, Cothrel, and Wellman (2005). The employees using instant messaging were able to manipulate their login status even if they were away from their desks; this made supervisors believe that the employees were always in their offices, which was not always true.

Expert power refers to infopower emanating from B's dependence on A's knowledge. This phenomenon has been identified in connection with various sorts of technology experts (Crozier, 1964; French \& Raven, 1959). IT experts that populate IS units in organizations present a current 
example: system design choices that IT experts make and the timing of system changes they determine can sway many employees to involuntary behavior (Travica, 2008). In addition, expert power can manifest itself at the group level, thus being wielded among professional groups (see Barley, 1986, 1990; Markus, 1983). Alike to other types of power, expert power surfaces in the hierarchical organization, while it distinguishes itself for violating the usual top-down flow of power. For example, a secretary or a professional that knows how to operate an IS may have expert power over their technically ignorant boss.

The next segment of infopolitics is infopolitical agenda (or infoagenda), which refers to goals, strategies, and tactics related to achieving and maintaining infopower as well as other infopolitical goals. Self-interest, including the aggregation of it at the group level, is the most productive generator of infopolitical agendas. Research identified phenomena akin to infoagenda among financial accountants who used a new financial information system to change financial and managerial accounting in a pharmaceutical company (Markus, 1983). Myers and Young (1997) exposed a hidden agenda of managers in a health provider enterprise in New Zealand. In an attempt to compete more effectively for government-controlled funds, the managers pushed for implementing a system module for tracking time-based costing of services, which was not included in initial system requirements. Travica $(2005 \mathrm{a}, 2005 \mathrm{~b})$ discovered infoagenda aimed at monopolizing knowledge of managing a voluntary organization, which was the main power source for a clan in the organization.

The last segment of infopolitics is the dichotomous couple infopolitical fight and infopolitical flight. The fight aspect captures the confrontation against an opposed party, while the flight refers to coalition building with the goal of promoting one's agenda, usually at the expense of some opposed party. Research on American local government organizations found that the adoption of computers "automated the bias" of the previously present distributions of infopower (Danziger et al., 1982). Powerful groups remained intact and used electronic information in the policy process in the way that served their interest. In the IVO parlance, the privileged groups joined in an infopolitical flight in order to influence design of the system in their favor. Furthermore, in Lapointe and Rivard's (2005) study of electronic medical record systems introduced in several Canadian hospitals, doctors joined in a flight against systems' champions in order to oppose changes in information management they viewed as imposing non-professional work on them.

\section{Methodology}

The study compares two enterprise self-service systems in two companies - HRMS at Utilities Company and CRMS at Telco. Each was investigated via a case study. At the time of data collection, HRMS was about one year old, and CRMS was in the fifth year of its life cycle. Although the data were not collected in the same period, each case study used the same research question: What are the critical factors for adoption of the self-service system? In addition, each case study deployed the same theoretical framework of IVO and methods of data collection and analysis (discussion further below). The final step in data analysis on the sets of data resulting from the two cases was the application of a research model based on IVO (see Figure 2). It extends the general model depicted in Figure 1 by showing relationships between specific infopolitical concepts and system adoption.

Markus's (1983) study can illustrate the relationships established in the research model. The model suggests that there are mutual influences between infopower and infopolitical agenda. As Markus's (1983) findings indicate, the prospect of a new financial IS shaped the infopolitical agenda of financial accountants sitting in the corporate accounting unit. Acquiring more control over accounting data, procedures, and standards became a goal on their agenda of change. Since this increased control is one kind of infopower, it follows that infopolitical agenda influenced infopower of corporate accounts (in the research model, note the arrow between two aspects and its 
direction). For managerial accountants in the corporate divisions, this relationship worked in the opposite direction: the infopower divisional accountants had enjoyed traditionally made them create a conservative infopolitical agenda (note the reverse direction of the cited arrow in the research model).

These opposite agendas and the asymmetric distribution of infopower had differing effects on adoption of the system. Correspondingly, the research model establishes unidirectional relationships between infopower and infopolitical agenda, on the one side, and system adoption, on the other. Furthermore, the shared infopolitical agenda and the infopower concerns made each accountant group exhibit group political behaviors that IVO terms infopolitical flight/fight. These relationships are also depicted in the research model. The model assumes that flight can influence fight as grouping the forces precedes an attack. Finally, infopolitical flight/fight influence system adoption, as the research model shows. The flight/fight of corporate accountants had a positive effect on adoption of the new system, while the opposite was true of the divisional accountants' flight/fight.

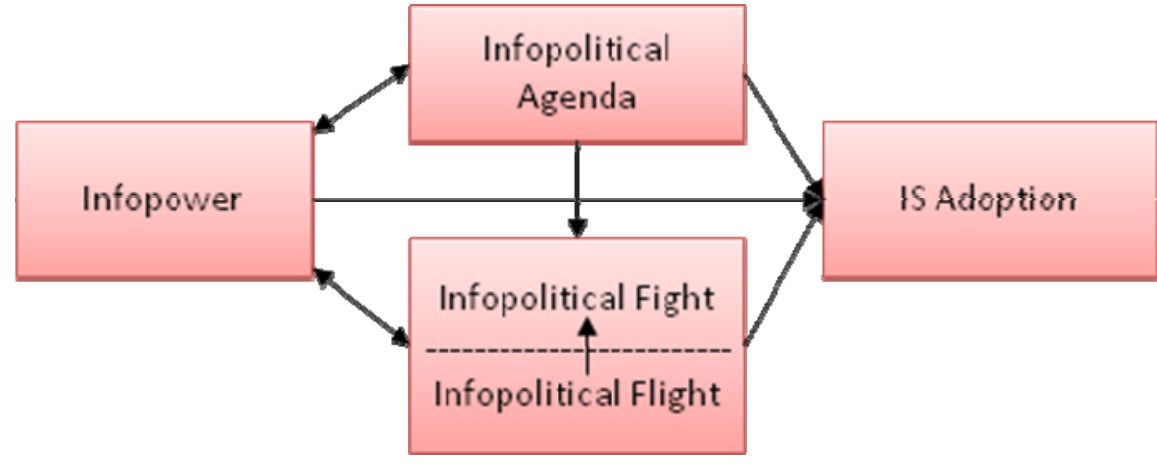

Figure 2. Research Model

The data for the present study came from larger datasets resulting from case study investigations in two companies, which deployed case study methods (Lee, 1989; Yin, 2003). These studies used an interpretivist epistemology and a mix of qualitative methods (Charmaz, 2006; Glasser \& Strauss, 1967 Orlikowski, 1992; Suchman, 1987; Tedlock, 2000) and quantitative methods (surveys).

Qualitative data collection consisted of intensive interviewing, observation of systems use, and analysis of documents. Interviewed were 33 persons at Utilities Company and 16 at Telco. The former sample was representative regarding the departmental, hierarchical, and occupational differentiation, while the latter sample captured $50 \%$ of the licensed users in professional roles and four executives.

Interviews were tape-recorded with consent of the respondents, and notes were taken during each interview. Design of interviews varied from semi-structured to structured ones (in case of executives). A semi-structured interview would start by asking a respondent to describe his/her main tasks and the role of the system in them. Then, probes would be used in order to learn about details of information and IT aspects involved in the tasks, advantages and disadvantages of the system, and support they received for using the system by management and IS staff.

Interview notes and transcripts were coded iteratively during data collection, and the researcher's learning about "issues" was advancing with time. Once coding category acquired initial contours, the interviewing became more focused. The goal from that point on was to drill down into details of the emerging constructs and their relationships. The IVO-based macro categories of infopower, infoagenda, and infopolitical fight/flight infopolitics emerged only by the end of coding process. As already mentioned, the final step in data analysis was the application of the research model 
discussed in this section. This step provided a bridge between the two cases, thus leading to the present comparative case study.

Qualitative data were combined with quantitative data in the course of each case study and in final analysis (more below). The later accrued from surveys that were administered by the end of data collection in each company. The surveys drew on preliminary findings and aimed at (a) validating some qualitative findings, (b) assessing the frequency of certain perfections and behaviors, and (c) obtaining precise figures on system adoption (in the case of HRMS). This article discusses just those survey results that are relevant for understanding the role of infopolitics in systems adoption. The response rate at Telco was $50 \%$ out of 24 sampled (which was the size of the entire population of users). At Utilities Company, the response rate was $61 \%$ out of 320 sampled (the user population numbered 850 ).

\section{HRMS at Utilities Company}

Utilities Company is a large government-owned enterprise that generates and distributes electrical power. It is organized as bureaucracy with elements of matrix organization in its engineering division. The HR function is centralized. The system studied is a mySAPTM self-service application for HR management. It contains two modules - one is for all employees to enter and query their time, expenses, travel, and professional development, and the other is for 700 managers to lookup and approve these electronic data and documents. This report focuses on the management module (from now on, HRMS) that posed challenges to the company. HRMS was introduced with the goal of reducing the clerical staff ratio over time.

The study found that HRMS was moderately adopted after about a year into the "shakedown phase" (Markus \& Tanis, 2000). The user survey this author conducted found that adoption ratios were in the lower to mid-60 percentages region. Complementing the lower adoption rate, the following shakedown problems surfaced: old processes were maintained (some paper-based), software was not easy to use, and users' skills were stalled. Managers and supervisors, making $80 \%$ of the user body, seriously challenged the system. This is in spite of the fact that they commonly praised the "better information" the system was supporting. This benefit could not offset their criticism of the IT built into the system, which translated into a long list of usability problems. But the root of the managers' dissatisfaction was reaching deep down to the process side.

A number of respondents characterized new processes as the core challenge. One of them phrased it succinctly: "There have been two changes that have come simultaneously - the process change and the tool. So, the tool is maybe getting blamed for part of the process." Line management rejected the process (many processes, indeed) because they were not willing to do more work than before the implementation of HRMS. As one respondent put it, "The introduction of the application has created more work for managers." Instead of obtaining documentation and reports from the clerks, managers were put in the seat of direct system users and obliged to do all the work by themselves. They did not want to operate the system, even though, as mentioned above, they did appreciate information that the system was supporting.

\section{Infopower Winners Push for HRMS}

The upper-level management in both the HR and IS function have pushed for HRMS adoption. These are the system's champions. HR executives have explicated clearly an intention to make supervisors and unit managers use the system for control and decision making purposes, as illustrated later in this paper by the citation on aligned infopolitical agendas in Table 1 . This move constitutes a change compared to how approval of time and expenses were done through clerks before the implementation of HRMS. While believed to be desirable and even necessary, such a change is not accepted enthusiastically by those who are supposed to lead system adoption-line 
management in corporate divisions. The system champions are fully aware of this problem. The same HR executive ascertained that managers want the clerks to continue doing approvals "like they were doing it before." His technologist counterpart agrees: "Division managers are used to having their secretaries delegate and approve stuff, and then inform them when things are irregular or there are exceptions. It is a turf call." An IS executive pointed out to insufficient technical skills of managers as a cause for resisting HRMS.

Although carrying aligned infopolitical agendas, the HR and IS executives do come from different perspectives. HR executives have in mind economic drivers. As one put it, "SAP is our core system. [...] We have a very large investment in SAP and we have to drive that value." A strategic goal in the background has to do with a rationalization of administration professed by top executives. As the CEO put it, "I think the ratio of clerks to the rest of the workers will probably go down as a percentage [...] because of computers." From the technologists' perspective, adopting HRMS is simply a matter of keeping up with progress. "Should you turn your organization around SAP?" The head of the SAP group asked this question rhetorically only to answer it with no hesitation; "I think you do, and you better come up with good reasons why you're doing it differently." These goals indicate differences in political agendas that are directly linked to the concerned technology.

Since HRMS centralized the management of HR data, this change enlarged the turf of the system champions. When all the data needed for decision making become electronic and management decisions are made and recorded online, the beneficiary is the party who has this wealth of data at their fingertips - executives. Enter the fact of cross-functional integration of data. For instance, HR data flow into financial applications, allowing the creation of a big picture of the organization. Since executive reigns over finances, HR and IT are consolidated in the hands of one person, it is plausible that this accumulation of information feeds infopower-the capability to influence others based on possession of integrated information. This information engenders knowledge that propels the incumbent of this privileged role into a dominant position over those who depend on him for this knowledge.

As for the IS champions of HRMS, their source of power is in their technical expertise. They understand the systems better than others do and can influence its development trajectory with respect to timing and selection of applications. Here is an example:

We knew that, when we were going forward with the self-service, we weren't going to be offering everything at once. This was going to be a starting point for us. So, we picked the applications and those areas that we thought were the most important for the organization at this time, realizing that we were going to be offering more and more later. We decided we would offer some reports through the data warehouse with Phase II, and we actually offered some accounting reports as part of that, although that wasn't really related to the HRMS implementation. (Head of the SAP group)

Thus, the IT-based expertise is the source of expert power for the SAP group. Since it is inherent to an ERP system to penetrate deeply into organizational structure and processes, the SAP group's management has the opportunity to become a partner in shaping organizational design of Utilities Company. Therefore, their expert power feeds their social power. They indeed utilized subtle power techniques as the following illustration indicates:

The angle we come from is [that when] we're introducing a new report or we want to put in a new process, if you want to be able to handle it this way, which is a side-bar way of doing it, it's going to cost an additional $\$ 100,000$ or $\$ 200,000$. But if we do it this way, where everybody does it the same, you're going to save that. So, are you willing to accept doing this process a little bit differently for this one point? 
While being united in a push for the SAP-enabled changes, the HR and IS champions of HRMS can be uneasy bedfellows. Managers of the SAP group have to juggle numerous maintenance requests issued by users of different SAP modules (e.g., HR, finance, budgeting), whereas the HR executives feel as if they are not getting what they paid for:

"I am excited when I hear the term "Business Warehouse" [the SAP brand of data warehouse] that I am going to get something exciting, but it usually means that there are going to be delays, and that I am not going to get what I need. (...) I don't to this day understand why they can't deliver the reports... I can do almost anything I want in that silly system [Internet]. I don't even pay for it, it is just there. [...] And here you have developed this system for our corporation, and it doesn't do what I want it to do." (HR executive)

On the side of gaining more infopower are also two occupational groups that belong to early adopters - HR professionals and the clerical staff. Working in the centralized HR function, HR professionals worked as eager beavers in accepting HRMS. Indeed, they became a change agent, supporting line managers though formal help desk and work relationships and via informal communications. The HR function performed a creative and energetic adoption campaign and it has maintained help desks and provided mentoring to the divisional rank and order employees. One HR manager characterized their job as "helping management get the skills we need to manage the company." The HR professionals interviewed shared the attitude that that HRMS is a step in the direction of providing this help. HRMS appears helpful in emboldening the expertise of HR professionals (e.g., in labor force planning), which may be a source of expert power over those depending on this expertise (e.g., line management).

Clerks are the other early adopt of HRMS. They are comfortable with it, sometimes act as educators to their bosses, and can be critical of non-adopters. Note this scolding of one executive secretary, "Stop bitching, and just do it!" In addition, the clerks see a value in HRMS. One of them noted, "Well, now I don't know how you would work through a day without computer. So things have certainly changed a lot." The new distribution of infopower works for the clerks since their bosses do not hesitate to delegate system-based work to them. One secretary explained, "I check everything over and approve, as in expenses. And then it goes to the appropriate supervisors and then they do the final approval." This indicates that clerks still have control over data as a source of infopower. But there is also a component of expert power in this relationship, since clerks have IT skills that superiors reject and, thus, put themselves in a dependent position.

Clerks have also maintained their infopower and increased their expert power vis a vis workers. Here is an illustration of this prolonged asymmetry:

"Most of technicians would not enter their own time because this is not their specialty; $[. .$.$] they don't know the ins and outs of time entry as far as their un-$ ion agreements, what they are entitled to, what correct codes and accounting numbers to use." (Clerk)

\section{Infopolitics of Resistors}

Aligned against the champions' agenda of changing management processes by HRMS is a significant part of line managers (the mid- and supervisory management). Their agenda is to reject what they feel is extra work on their side. They believe this work is HR administration work that does not add value to line managers' work. Here are some illustrations:

"Some of the process changes have downloaded a lot of responsibility and added a lot of work in our area [expenses approval]." (A manager) 
"Now all of that admin is done at the supervisory level and it takes a lot of their time, and their plates are full trying to run the day-to-day operations of the department." (A supervisor)

"We have pushed a clerical function from a HR advisor onto supervisors and managers and you really wonder if it is productive use of the supervisors and managers time." (A manager)

Information-related power of divisional management has not changed in relation to subordinates. However, the distance in infopower between them and corporate management has increased with the centralization of HR information. Therefore, the system brings no power gain to divisional management, while they can experience a loss of it.

If not rejecting HRMS directly, managers would like it to be more flexible in terms of access. Technically, this runs against the logic of the SAP module used for managing user roles, which contains predefined authorizations corresponding to organizational hierarchy. But management persists in requesting more flexibility even at the expense of temporarily sharing infopower down the ladder. Several managers argued that their administrative workers should have broader power over HRMS than the current authorizations allow. For example, managers should be allowed to assign substitutes for doing online approvals and be absent from the job. Therefore, divisional managers tend to delegate both some infopower and certain authority to clerks.

Workers reside at the bottom of the infopower distribution. With no technical skills and necessary knowledge, and deprived from access to HRMS, workers are directly dependent on clerks for data entry. Two in three clerks do time administration for field workers, which can take up to $30 \%$ of clerks' time.

Thus, the workers - one third of the employee body - are an underdog in the scenario of implementing the self-service HRMS at Utilities Company. Another implication of this scenario is that the prolonged deployment of clerks in the time keeping task brings into question the strategic goal of rationalizing administration and saving on administrative costs, which has been touted as a strategic goal behind HRMS.

The next section discusses the system investigated in Telco, and Table 1 by the end of the section summarizes in a comparative fashion the findings on both companies.

\section{CRMS at Telco}

Telco is a large private company that provides landline and mobile telephone service, as well as cable TV and access to the Internet. A government monopoly for decades, Telco faced a competitive market in the 1990s and was privatized by the end of the decade. The CRMS studied is based on Siebel ${ }^{\mathrm{TM}}$ software, and it is used in the sales and the marketing department. The marketing department is in the focus of our analysis because that is where CRMS is used by professionals in the self-service mode. CRMS was introduced with a strategic goal of obtaining an integrated picture of the customer.

The study found that marketing professionals adopted CRMS to a very limited extent, using it exclusively for the creation and storing of marketing campaigns. There were 22 licensed users of CRMS, which made 13\% of the department's employees. On the average, CRMS was used from "sporadically" to "once-twice a week," the mean usage being equal to 2.82 on a five-point scale (1=low, 5=high). 


\section{Zigzag Life Trajectory}

CRMS has been going through an irregular life cycle. It started in the early 2000s, with a grand vision of developing an integrated picture of customers in a local corporate market. System design was refined several times, and each version specified a broad functionality that was supposed to be added in a multi-stage development process. The planned subsystems included a product catalogue, order entry, order management, and Web-based front-end for accessing both the catalogue and ordering system.

The target market shifted to local consumers after Telco acquired, in 2004, a company that had a strong footing in the national corporate market. This company had its own CRM system. The development of CRMS materialized in implementing a module for marketing campaigns in the marketing department. In the sales department, modules were implemented for customer master data and for a basic tracking of customers across Telcos' four lines of business (services used and the total annual expenditure). Beside this acquisition, another event possibly made an impact on the trajectory of CRMS: two top executives, who acted as system champions, left the company. Following the acquisition and the change at the top, the CRMS development was halted and reduced to a necessary maintenance.

All the interviewed higher echelon managers who were involved in the system planning assume that the cited acquisition precipitated the strategic shift in the target market and delayed the planned system development. However, there is no full agreement regarding the specific obstacles that the acquisition had brought up, and the interpretations range from pointing to different IT infrastructures to a direct obstruction of CRMS. Why did the system development not proceed as planned after the shift to consumer market? The respondents agree that cost of the orders management module was prohibitive. However, nobody could explain why the assessment of the module's cost did not show up clearly in the feasibility study.

\section{Poor Data Yield No Infopower}

The heart of any IS is data. For the system heart to be healthy, the data have to be accurate, complete, timely, and easily accessible. Such data are likely to become meaningful in the mind of IS users, to facilitate knowledge creation, and ultimately to help the users perform more effectively and efficiently on their job. The IT built into the system needs to support quality data. Early in the systems production stage, IT usually exhibits problems of user interface, functionality, processing speed, etc. Technology problems may dominate users' perception of the system. The HRMS case is illustrative in this respect. Once these difficulties are overcome, system data come to the foreground and the system's evaluation is shifted to the contribution of data to business. This is exemplified in the CRMS case.

The study found that CRMS did not pass the quality test of the users. Respondents pointed to a number of data problems, such as the incorrect customer data, missing feedback to marketing campaigns, missing data on customer profiling, and missing data flows between the marketing and sales department. Here is how a marketing professional summarized it:

CRMS is a system in which all four wheels are coming off. The first wheel is information accuracy, the second is the use of information in campaigns, the third is the tracking of campaign results, and the fourth is how CRMS is used to service customers. All the wheels need fixing and management needs to re-embrace CRMS.

Elaborating on problems with the CRMS data, customer addresses are not updated regularly mainly because it is not clearly defined who should do this - the marketing or the sales department. The survey conducted as part of the study found that the marketing professionals thought that this data governance issue was not resolved. (The survey question read, "It is clear to me who 
owns the CRMS data that I need for my work," and the mean was 2.36 on the $1-5$ point-scale, $1=$ minimum agreement.)

Most of the respondents cited unsatisfactory accuracy of data as an additional problem. For some of them, incorrect data were the reason to quit using CRMS after initially adopting it and to switch to using alternative, sometimes "makeshift," systems (e.g., Excel and Lotus Notes applications). The study's survey found that this behavior was frequent. (The item "I can choose to use alternative software tools rather than CRMS to complete a certain task without being criticized by my manager" was strongly correlated with the extent of CRMS usage $-r=0.70$.)

The feedback to marketing campaigns are collected only by external sales channels (telemarketers and a retail channel), and these cannot access CRMS. Consequently, the users do not expect to find market response data in CRMS, which significantly limits the system's scope to storage of marketing campaigns. Explained one respondent, "You enter your campaign [into CRMS] and you get the database person to attach the customer list. Then you close it and forget about it because nobody ever enters any results into CRMS." Another concurred; "CRMS is the last thing that people remember to do because I don't get any information out of CRMS."

Another limitation of the CRMS data is that it does not contain details useful for customer profiling. Instead, customer profiles are derived from the ordering and billing data that are stored in legacy systems; these data are ported to a data warehouse, and data mining tools are applied on them. The head of the marketing department assessed that CRMS had no business value from the perspective of customer profiling. This person expressed a determination to keep investing in the data warehouse/data mining rather than CRMS. A professional concurred, pointing to a large discrepancy between the current state of CRMS and the grand vision behind it: "There is a huge gap between the vision of CRMS and reality. CRMS was sold on the basis that there would be one customer. But this didn't happen."

Data flow between the marketing and the sales department via alternative channels rather than by CRMS. One aspect of this is indicated above - nobody enters the market feedback data into CRMS, neither the sales vendors nor Telco's sales department. Another aspect concerns the marketing department. Although marketing staffs enter marketing campaigns into CRMS, they really push campaigns to the sales department via electronic bulletins. Trying to ensure that campaign data reach the sales department, the marketing campaigners use this alternative channel.

The study investigated what actually was happening in the sales department and found that sales representatives did not use CRMS for promoting new products and services. Rather, they would typically answer the customer call (possibly triggered by a campaign) and use marketing electronic bulletins and some other applications in order to cite offers. The sales staff has mainly used CRMS as storage of customer master data and a vehicle for customer verification. The third aspect of eliminating CRMS from inter-departmental communications refers to customer complaints. These have been collected by the sales staff who would transfer them to the marketing department, again, outside of CRMS (e.g., via Lotus Notes applications). Overall, CRMS has failed to support cross-departmental data flows, precipitating dissatisfaction among users on the marketing side.

The limited flows of data between the marketing and sales department reflect and reinforce the existing organizational structure. Participants in the study share the opinion that a model of silo still best describes the organizational structure. In a silo structure, information management is confined to organizational departments and cross-department information flows are minimal. While progress has been made in breaking the silo structure around Telco's lines of business (landline phone, the Internet, etc.), the old functional organization has remained resilient. Some respondents pointed that this relic could help in explaining why governance over customer data was never clarified and why the two departments could not coordinate better their uses of CRMS. 
The missing pieces and ambiguities in the large picture are contrasted by certainty that characterizes the situation in the users' trenches. And the users do not spare criticism. The coding process revealed categories of "disappointment", "purposelessness", "unworthiness" attributed to CRMS, each of these having a higher frequency of instances. Here are some illustrations:

- "CRMS is sort of a system that everyone loves to hate."

- "CRMS is a multimillion dollar mistake."

- "I stopped using it just because there is no point; it's a waste of time."

It is clear that CRMS supports a very limited set of tasks related to creating and storing marketing campaigns. But all other aspects of managing customer relationships managing markets are outside of the system's scope. As such, CRMS fails to support most of the marketing professionals' job. Put another way, CRMS does not empower these professionals. The poor CRMS data do not help professionals to develop knowledge that can be a source of expert power. The ill "heart" of CRMS limits action even of eager learners and avid users of electronic tools.

Indeed, there are such users among the marketing professionals. And all the professionals participating in the study clearly articulated a need for detailed, accurate, and timely customer data, that is, for systems support to such data. As the company's markets expand and competition increases, a marketing expert needs these data in order to understand customer groups and to predict market trends. In absence of CRMS support, legacy systems for customer order management and for billing fill the void. The data are fed into a data warehouse and data mining is applied to it in order to segment the markets, understand customer behavior, and develop if-then scenarios preceding a marketing campaign.

Some of the participants in the study run data mining tools on their own, while others rely on the company's systems professionals. The combination of legacy systems, which have transaction processing and some reporting capabilities, and data warehousing/mining has a crucial role in the job of many marketing professionals. They are enabled to exercise their general marketing expertise (tacit knowledge included) and to advance it by becoming specialists for the respective markets. Based on market analysis these professionals can run, they are capable of convincing their boss of the feasibility of a contemplated marketing campaign and to get the campaign approved. In contrast, the poor data and functionality of CRMS disqualifies it as a vehicle for exercising expert power this way (or any other way, for that matter).

The user dissatisfaction and lower system adoption have a parallel in losses in organizational performance. Because CRMS does not capture the user feedback to marketing campaigns when customers call the sales department to order a new service, the marketing staff cannot establish a causal connection between these campaigns and orders. The consequence is that marketing campaigns are pushed into the market, while their effects can just be hypothesized by taking changes in the volume of sales as a consequence of the campaigns. In addition, customer service suffers because of incomplete and incorrect customer data. Moreover, inter-departmental processes are less efficient (e.g., the marketing campaign process and the customer complaint process).

It is plausible that the marketing professionals could have pushed for improving the system's data had they experienced some benefit of gaining power based on the data, that is, infopower. This line of reasoning leads to the chicken or egg problem. Is there any solution to it?

\section{Disowning CRMS}

There is an antecedent to rejection of CRMS by marketing professionals, which removes the chicken or egg problem signified in the previous section. Indeed, many respondents hinted that CRMS was so limited because managers had not given it proper care. Here is how one respondent 
pointed to this problem, "I was using CRMS for the first year that I was in my function, and I was like John the Baptist in the wilderness by myself. You feel a little silly after awhile." This former user of CRMS explained that using the system was entirely his initiative and that managers provided no encouragement for it. Another respondent, a sporadic user of CRMS, hinted in the same direction, and suggested that users did not know what course had the managers set for CRMS.

Table 1. Summary of Findings

\begin{tabular}{|c|c|}
\hline HRMS at Utilities Company & CRMS at Telco's Marketing Department \\
\hline $\begin{array}{l}\text { Self-service across departments, several user } \\
\text { groups (HR Professionals, line supervisors and } \\
\text { managers) }\end{array}$ & $\begin{array}{l}\text { Self-service by professionals in the marketing } \\
\text { department }\end{array}$ \\
\hline $\begin{array}{l}\text { Low adoption by supervisors and managers in } \\
\text { the first year of HRMS production stage }\end{array}$ & $\begin{array}{l}\text { Low adoption by professionals in the mature } \\
\text { stage of CRMS }\end{array}$ \\
\hline Infopolitics aggravates system adoption & Infopolitics has contributed to low adoption \\
\hline \multicolumn{2}{|c|}{ Infopower } \\
\hline $\begin{array}{l}\text { - Line (divisional) management has no gain in } \\
\text { infopower, while losing some to the corporate } \\
\text { executives } \\
\text { - Clerks maintain control over data and poten- } \\
\text { tially increase it as managers are willing to } \\
\text { share access to HRMS; clerks also increase } \\
\text { expert power based on new IT skills over man- } \\
\text { agement and workers } \\
\text { - IS managers increase IT-related expert power } \\
\text { - Workers are deprived of infopower and fully } \\
\text { dependent on clerks }\end{array}$ & $\begin{array}{l}\text { - CRMS does not create a basis for extending } \\
\text { expert power of professionals since it has no } \\
\text { appropriate data and functionality for creating } \\
\text { knowledge of customers that some other party } \\
\text { would depend on }\end{array}$ \\
\hline \multicolumn{2}{|c|}{ Infopolitical Agenda } \\
\hline $\begin{array}{l}\text { - System champions on the IS and HR side } \\
\text { share the agenda of changing management } \\
\text { processes via HRMS, while disagreeing on de- } \\
\text { velopment priorities } \\
\text { - Managers' agenda is to reject HRMS and to } \\
\text { block the system champions }\end{array}$ & $\begin{array}{l}\text { - Professionals downgrade and reject CRMS } \\
\text { - The marketing and corporate management } \\
\text { marginalized CRMS in their agendas }\end{array}$ \\
\hline \multicolumn{2}{|c|}{ Infopolitical Fight/Flight } \\
\hline $\begin{array}{l}\text { - Divisional managers and supervisors joined } \\
\text { in a flight against HRMS' champions, and } \\
\text { openly to fight them } \\
\text { - Struggle between IS and HR executives over } \\
\text { priorities in system development }\end{array}$ & $\begin{array}{l}\text { - Marketing and corporate management block } \\
\text { development of CRMS } \\
\text { - Professionals abandon CRMS }\end{array}$ \\
\hline
\end{tabular}

How common is this sort of conviction? It is indeed quite common, according to the study's survey. Here are the relevant questions and their answers indicated by the means on the five pointscale (1=low agreement): 
- The attitude of my department managers toward CRMS assures me that CRMS has a bright future (2.36).

- I am certain that the upper management in my firm has been providing appropriate support for CRMS. (1.91).

- From the perspective of my professional needs, I would characterize the present implementation of CRMS as unsatisfactory. (4)

While indicating a significant frequency of the conviction that CRMS has been improperly managed, these findings also validate the interview data. Interviews with executives confirmed that CRMS was a marginalized system in the management agenda. Congruently with the marketing head's withdrawal of support of CRMS (see above), the head of consumers division saw no future for CRMS unless the new vendor unleashed some new cost-effective technological solutions. (In the course of the study, Oracle acquired Siebel, and Telco's database system was Oracle.) Other executives shared the opinion that no further major investment in CRMS was likely, even though they claimed allegiance to the vision of the integrated customer view without deleting CRMS from it.

By drying up the budget for CRMS and deleting it from system development plans, strategic management effectively disowned the system. Flying in the same direction, operational management has provided no enforcement and incentives for using CRMS. Thus, managers at both levels share the same infopolitical agenda and join in the flight of withdrawing support for the system. The infopolitics of managers is responsible for the poor state of the CRMS data. These data, as discussed above, disallow professionals to build their expertise and ultimately infopower upon CRMS. Therefore, the professionals' rejection of the system has the primal cause in the managers' withdrawal of support to it.

Put another way, both parties have disowned CRMS. The behavior of managers and professionals created a self-amplifying positive loop of abandoning the system. While the managers' behavior was undoubtedly influential, the professionals made a choice on their own - many to completely abandon the system, others to keep tinkering with it for limited purposes. The decision making discretion that Telco's marketing professionals enjoy (similarly to their colleagues in other companies) has made them an accomplice in disowning CRMS. This study reveals that motives residing in the realm of infopower bear a responsibility for behavior of these professionals. Table 1 summarizes in a comparative fashion the findings discussed in this section.

\section{Discussion}

This comparative case study investigated systems adoption factors associated with self-service enterprise systems in two companies. It should be noted that the constitutive cases have no full match since the systems studied differ in purpose, life cycle stage, IT deployed (ERP software and hardware configurations), information content, users, and organization type (public vs. private). These differences point to a limitation of the study. Still, both systems are of the selfservice type, which is the crucial characteristic for this study. In addition, both systems process transaction data, use typical client-server configurations, are costly, and reside in companies that are of a large size. These similarities alleviate the impact of the cited limitation on the validity of the comparison of the systems.

Aiming at identifying critical factors for adoption of the self-service systems, the study located these factors in the domain of infopolitics. If a gain in infopower is in prospect, infopolitics has a facilitating effect on adoption of a system. This happens with the executives, professionals, and clerks in Utilities Company. Their infopolitical agendas and behavior is congruent with the real and potential gains in infopower. 
The missing infopower gains lead to rejecting the systems studied. This applies to line managers in Utilities Company who face no pay back in terms of increased infopower, while having to do more work as they operate HRMS. They treat HRMS as an unwanted child. For the same reason, the marketing professionals in Telco behave in a similar way. These professionals can use CRMS just to a severely limited extent and the system's poor data cannot enable them to exercise and maintain marketing expertise that ultimately translates into infopower. The professionals' stance is ultimately determined by the managers' unsupportive infopolitical agenda and by their corresponding flight in denying CRMS. Professionals and managers have disowned CRMS. Therefore, the perspective of infopolitics can help in predicting prospective adoptive behavior

These findings signify the study's theoretical contribution: dynamics of infopower, infopolitical agendas, and infopolitical fight/flight help understanding the adoption of self-service systems. This type of system promotes casual users into regular users, who are now deprived of the convenience of relying on clerks. Traditionally users of transactions processing and reporting systems, clerks were specially trained and had to operate systems as part of the daily job. When managers and professionals become regular users of such systems, technology does not take the center place in the professional development and work of these occupational groups. In addition, these nascent users bring with them power of choosing work methods (again, contrary to clerks). These new moments complicate adoption of self-service systems that adoption theory and practice need to account for.

The identification of infopolitics as a factor of self-service systems adoption complies with and extends the theory of system adoption. For instance, the infopower benefit can be understood as one aspect of perceived usefulness of IT in the Technology Acceptance Model (TAM) (Davis, Bagozzi, \& Warshaw 1989). However, the IVO inquiry provides a more analytical look at the benefits. Recall that the resistors at Utilities Company appreciated the "better information" HRMS supported. But this aspect of perceived usefulness paled in contrast to the missing benefit of infopower increase. This contrast underscores the importance of addressing infopower while investigating perceived usefulness of an IS.

In contrast to the TAM-like inquiry that can provide a static self-assessment of IS-related power benefit, the IVO approach illuminates dynamics of infopower via its relationships with infoagendas and infopolitical fight/flight. This expanded view may have an important repercussion for research: while reflecting variation in infopower, infoagendas and hostile/supportive behaviors are easier to read than infopower itself. Neither Telco's professionals nor Utilities Company's managers hid their adversity toward the respective systems. Moreover, Telco's professionals made it clear that their adversity to CRMS was on their long-term agenda. Therefore, infoagendas and infopolitical fight/flight allow the researchers to reach down to the opaque realm of power.

The stance of infopolitics also contributes to broadening the fundamental model of informing science, that of an informing system. An informing system consists of informer, delivery system, and client, placed in their contexts (Cohen, 1999). The comparative case presented in this article paints the relevant contexts and their roles in the informing process. In Utilities Company, there is a disconnect between the client (line management) and the informer (employees entering their time and expenses data, and clerks doing the same on the behalf of blue-collar workers). The delivery system (HRMS) cannot interface the two because of the blocking impact of the infopolitical factor on the client side. In Telco, the delivery system (CRMS) also fails to interface the client (marketing professionals) with the informer (data creators inside and outside the Marketing department). The infopolitical factor, however, may work not only on the client side but also on the informer side, determining the poor quality of the data input. Therefore, the case demonstrates that the infopolitical context makes an impact both on the delivery system and on the quality of informing. 
Moreover, the study advances empirical validation of the IVO framework, by adding the aspect of infopolitics to previously completed research on other IVO aspects (Travica, 2005a, 2005b, 2007, 2008). Taken together, these contributions add to understanding power and politics in the context of IS and IT (Danziger et al., 1982; Jasperson et al., 2002; Markus, 1983; Orlikowski, 1992; Travica, 1999; Zuboff, 1984).

From the practical perspective, this study raises some important questions. System champions and executives at Utilities Company should pay due attention to the challenges that infopolitics in their organization poses to adoption of HRMS. The zero-sum infopower game, which was initiated by implementing HRMS, places divisional (line) management at the losing end of the new power distribution. Revisiting this delicate realm and identifying potential gains that would improve the loser's position would be the course to follow. In this bureaucratic organization, where hierarchy and every bit of power do matter, compromising rather than competing is a more realistic option when a new self-service system for managers is implemented. In addition, the strengthening of the clerks' infopower position in relation to line management and blue-collar workers is an effect that deviates from the strategic goal of reducing the clerical staff. Either new means to this end outside of HRMS are to be identified or the goal needs a revision. The former move, however, undermines the charter behind HRMS. These dilemmas indicate a larger challenge that concerns management self-service systems in any similar organization: How to position infopolitically this type of system to be viewed as a universal managerial tool rather than a clerical tool? The "universal" character implies that infopower gains are not accumulated exclusively in hands of executives.

In comparison to HRMS, chances of resolving the challenges perplexing CRMS at Telco are miniscule, if any. CRMS had past the adoption phase and is deeply in the production phase. The system clearly follows a descending path. For the stakeholders at Telco, this case should become a page in the company's guide for creating systems strategy and managing self-service systems. The page should remind of how infopolitics and improper systems management can create a vicious loop that eventually chokes an expensive system. For other organizations implementing self-service system for professionals, this case may be a warning to keep off such a dangerous pitfall.

Note: This study was supported by a URGP grant from the University of Manitoba for Project \#31532.

\section{References}

Barley, S. (1986). Technology as an occasion for structuring: Evidence from observations of CT scanners and the social order of radiology departments. Administrative Science Quarterly, 31, 78-108.

Barley, S. (1990). The alignment of technology and structure through roles and networks. Administrative Science Quarterly, 35, 61-103.

Beniger, J. R. (1986). The control revolution: Technological and economic origins of the information society. Cambridge, MA: Harvard University Press.

Boisot, M. (1987). Information and organizations: The manager as anthropologist. London: Fontana/Collins.

Boisot, M. (1998). Knowledge assets: Securing competitive advantage in the information economy. Oxford, NY: Oxford University Press.

Bradshaw-Camball, P., \& Murray, V. (1991). Illusions and other games: A trifocal view of organizational politics. Organization Science, 2(4), 379-398.

Burns, T., \& Stalker, G.M. (Eds.) (1961). The management of innovation. London: Tavistock Publications. 
Charmaz, K. (2006). Constructing grounded theory. London: SAGE.

Cohen, E. (1999). Reconceptualizing information systems as a field of the transdiscipline informing science: From ugly duckling to swan. Journal of Computing and Information Technology, 7(3), 213-219.

Crozier, M. (1964). The bureaucratic phenomenon. Chicago, IL: University of Chicago Press.

Danziger, J., Dutton, W., Kling, R., \& Kraemer. K. (1982). Computers and politics: High technology in American local governments. New York: Columbia University Press.

Davis, F., Bagozzi, R., \& Warshaw, P. (1989). User acceptance of computer technology: A comparison of two theoretical models. Management Science, 35(8), 982-1003.

French, J., Jr., \& Raven, B. (1959). The basis of social power. In D. Cartwright (Ed.), Studies in social power (pp. 150-167). Ann Arbor: University of Michigan.

Glasser, B., \& Strauss, A. (1967). The discovery of grounded theory. Chicago: Aldine.

Goffman, E. (1967). Interaction rituals: Essays in face-to-face behavior. Chicago: Aldine.

Hanseth, O., Ciborra, C., \& Braa, K. (2001). The control devolution: ERP and the side-effects of globalization. The Data Base for Advances in Information Systems, 32(4), 34-46.

Hersey, P., Blanchard, K. H., \& Natemeyer, W. E. (1979). Situational leadership, perception, and the impact of power. Group \& Organization Studies, 4, 418-428.

Jasperson, J., Carte, T. A., Saunders, C. S., Butler, B. S., Croes, H. J. P., \& Zheng, W. J. (2002). Review: Power and information technology research: A metatriangulation review. MIS Quarterly, 26(4), 397459.

Lapointe, L., \& Rivard, S. (2005). A multilevel model of resistance to information technology implementation. MIS Quarterly, 29(3), 461-491.

Larsen, M., \& Myers, M. (1999). When success turns into failure: A package-driven business process reengineering project in the financial services industry. Journal of Strategic Information Systems, 8, 395417.

Lee, A. (1989). A scientific methodology for MIS case studies. MIS Quarterly, 13(1), 33-50.

Markus, M. L. (1983). Power, politics, and MIS implementation. Communications of the ACM, 26(6), 430444.

Markus, M. L., \& Tanis, C. (2000). The enterprise systems experience: From adoption to success. In R.W. Zmud (Ed.), Framing the domains of IT Research: Glimpsing the future through the past (pp. 173205). Cincinnati, OH: Pinnaflex Educational Resources.

Myers, M.D., \& Young, L.W. (1997). Hidden agendas, power and managerial assumptions in information systems development: An ethnographic study. Information Technology and People, 10(3), 224-240.

Mintzberg, H. (1979). The structuring of organizations: A synthesis of the research. Englewood Cliffs: Prentice Hall.

Orlikowski, W. (1992). The duality of technology: Rethinking the concept of technology in organizations. Organization Science, 3(3), 398-427.

Orlikowski, W., \& Yates, B. (1994). Genre repertoire: The structuring of communicative practices in organizations. Administrative Science Quarterly, 39, 541-74.

Pettigrew, A. (1972). Information control as a power resource. Sociology, 6, 187-204.

Quan-Haase, A., Cothrel, J., \& Wellman, B. (2005). Instant messaging for collaboration: A case study of a high-tech firm. Journal of Computer-Mediated Communication, 10(4), article 13.

Silva, L., \& Backhouse, J. (2002). The circuits-of-power framework for studying power in institutionalization of information systems. Journal of the Association for Information Systems, 4(6), 294-336. 
Silva, L., \& Hirschheim, R. (2008.) Fighting against windmills: Strategic information systems and organizational deep structures. MIS Quarterly, 31(2), 327-354.

Stein, A., Hawking, P., \& Wyld, D. (2005). B2E SAP portals: Employee self-service case study. In L. Lau (Ed.), Managing business with SAP: Planning, implementation and evaluation (pp. 90-109). Hershey, PA: IDEA.

Suchman, L. (1987). Plans and situated actions: The problem of human-machine communication. Cambridge, UK: Cambridge University Press.

Tedlock, B. (2000). Ethnography and ethnographic representation. In N. Denzin \& Y. Lincoln (Eds.), The handbook of qualitative research (pp. 455-486). Thousand Oaks, CA: SAGE.

Travica, B. (1999). New organizational designs: Information aspects. Stamford, CT: Ablex.

Travica, B. (2003). Information view of organizations: Contextualizing technology — technologizing context. Proceedings of AMCIS 2003, August 4-6, 2003, Tampa, FL.

Travica, B. (2004). Organizations as information processes. In A. Jacky, C. Isabelle, \& F. Marc, Process Management and Information Systems-Proceedings of Pre-ICIS Workshop, Washington D.C., December 12, 2004.

Travica, B. (2005a). Information politics and information culture: A Case Study. Informing Science: The International Journal of an Emerging Transdiscipline, 8, 211-244. Retrieved from http://inform.nu/Articles/Vol8/v8p211-244Travica.pdf

Travica, B. (2005b). Information view of organization. Journal of International Technology and Information Management, 14(3), 2005, 1-20.

Travica, B. (2007). Of monsters, divinations, costly dumbness and fumbling: Adopting a self-service system. Journal of Information, Information Technology, and Organizations, 2, 15-29. Retrieved from http://jiito.org/articles/JIITOv2p015-029Travica258.pdf

Travica, B. (2008). Influence of information culture on adoption of a self-service system. Journal of Information, Information Technology, and Organizations, 3, 1-15. Retrieved from http://jiito.org/articles/JIITOv3p001-015Travica470.pdf

Yin, R. (2003). Case study research: Design and methods (3rd ed.). Thousand Oaks, CA: SAGE.

Zuboff, S. (1984). In the age of the smart machine: The future of work and power. BasicBooks.

\section{Biography}

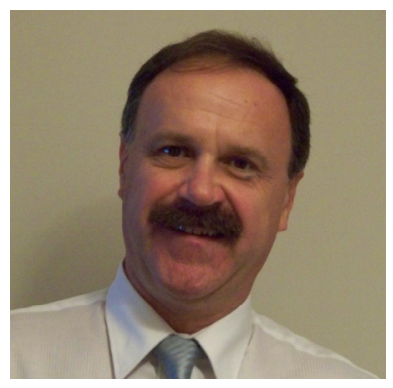

Bob Travica teaches information systems at University of Manitoba, and investigates organizations from the perspective of information and information technology management. His current preoccupations are with advancing an informing view of organization as a framework for research and teaching. 